\title{
A comparison of laws preventing unnecessary canine cosmetic surgery in Italy and in the Czech Republic
}

\author{
Valeria Quartarone ${ }^{1}$, Eva Voslářová2, Maria Russo ${ }^{1}$, Petra Doleželová2 $^{2}$ \\ Annamaria Passantino ${ }^{1}$ \\ ${ }^{1}$ Department of Veterinary Public Health, Faculty of Veterinary Medicine in Messina, Polo Universitario \\ Annunziata, Messina, Italy \\ ${ }^{2}$ Department of Veterinary Public Health and Toxicology, Faculty of Veterinary Hygiene and Ecology, \\ University of Veterinary and Pharmaceutical Sciences Brno, Czech Republic
}

Received October 23, 2010

Accepted January 18, 2012

\begin{abstract}
Many invasive procedures, including surgery (ear cropping, tail docking, and debarking in the dog), are performed on dogs for purely cosmetic reasons or convenience. These procedures, also known as "cosmetic surgery", fall into a variety of categories from the questionably unethical to the undoubtedly criminal, because they are mostly carried out solely to alter a dog's physical appearance. Although in several European countries these procedures are banned, except when performed by a veterinarian for medical reasons, veterinarians are often requested to perform them for various reasons. Though controversial, canine cosmetic surgery continues to be performed, reaching epidemic proportions. The authors summarize legislation, individual positions and veterinary attitudes regarding cosmetic surgery in Italy and the Czech Republic. Additionally, they explain the ways in which the law is being used in the two countries to prevent these unnecessary procedures, and how current and future anti-cruelty laws can stop unethical use of cosmetic surgery.
\end{abstract}

Ear cropping, tail docking, legislation, animal welfare, dogs

For centuries, dogs have been subjected to tail docking and ear cropping. Originally, these interventions were performed mainly for practical purposes to prevent injuries to working dogs, whereas now the reason is predominantly cosmetic. Today many show dogs have their ears cropped and tails docked just in order to give them a "traditional" look. Although some dog owners claim that they want to dock tails of their working dogs for hygienic reasons and crop their ears to prevent ear canal infections, there is no medical benefit to having a dog's tail docked or its ears cropped. Although these procedures may cause pain and distress, they are often done without any anaesthesia.

Tail docking is performed when a puppy is only a few days old ( $2-5$ days) and involves removing the hair from the tail and then clamping the tail with a rubber band at the desired length, at which point it is cut with a scalpel or cutters, stitched up, and bandaged. In the process, muscles, tendons, nerves, bone and cartilage are separated. Ears are cropped when a puppy is between six and twelve weeks of age, depending on breed and health conditions (Jensen 1950; Leonard 1958; Hancock 1968). Since ear cropping is a surgical operation and general anaesthesia is required, the procedure is generally performed by a veterinarian, although breeders and dog owners often undertake amateur attempts to it. Once the pinna is removed, the veterinarian splints the ears in the erect position using a splint or bracket. Post-operative pain treatment is rarely provided, even though ears, which are made of cartilage and nerves, easily bleed. A series of follow-up visits are carried out, during which the ears are handled, stretched along the edges, and re-taped. A far less common procedure is devocalisation, which involves the full or partial removal of a dog's vocal cords.

Address for correspondence:

Annamaria Passantino

Department of Veterinary Public Health

Faculty of Veterinary Medicine in Messina

Polo Universitario Annunziata, 98168 Messina

Italy

Phone: +390903503742

E-mail: passanna@unime.it

http://www.vfu.cz/acta-vet/actavet.htm 
Devocalisation surgery is performed solely to prevent a dog from barking or to "soften" a dog's bark. The procedure is almost always performed for the owner's convenience.

The question of canine cosmetic surgery illustrates the delicate balance between arguments on animal welfare and some "traditional" procedures. Such conflict partly depends on the lack of legislation on these issues. The authors will summarize the legal attitude in Italy and the Czech Republic towards these surgical procedures and briefly survey the relevant issues.

\section{Current legal situation}

There is no European Community Directive or Regulation against tail docking, ear cropping and other surgical operations. The only international treaty that mentions the aforesaid procedures is the European Convention for the Protection of Pet Animals (ETS No. 125) introduced by the Council of Europe (Council of Europe 1987). The Convention was signed by 22 countries (out of 47 member states of the Council of Europe) including Italy and the Czech Republic (Table 1).

Table 1. Field of application of the European Convention for the Protection of Pet Animals (Council of Europe 2011)

\begin{tabular}{|c|c|c|c|}
\hline$\underline{\text { Participating States }}$ & Signature & Ratification & Entry into force \\
\hline Austria & $2 / 10 / 1997$ & 10/8/1999 & $1 / 3 / 2000$ \\
\hline Azerbaijan & $22 / 10 / 2003$ & $19 / 10 / 2007$ & $1 / 5 / 2008$ \\
\hline Belgium & $13 / 11 / 1987$ & 20/12/1991 & 1/7/1992 \\
\hline Bulgaria & $21 / 5 / 2003$ & $20 / 7 / 2004$ & $1 / 2 / 2005$ \\
\hline Cyprus & 9/12/1993 & 9/12/1993 & 1/7/1994 \\
\hline Czech Republic & $24 / 6 / 1998$ & 23/9/1998 & 24/3/1999 \\
\hline Denmark & $13 / 11 / 1987$ & 20/10/1992 & $1 / 5 / 1993$ \\
\hline Finland & 2/12/1991 & 2/12/1991 & 1/7/1992 \\
\hline France & $18 / 12 / 1996$ & $3 / 10 / 2003$ & $1 / 5 / 2004$ \\
\hline Germany & 21/6/1988 & $27 / 5 / 1991$ & $1 / 5 / 1992$ \\
\hline Greece & 13/11/1987 & 29/4/1992 & $1 / 11 / 1992$ \\
\hline Italy & $13 / 11 / 1987$ & 19/4/2011 & $1 / 11 / 2011$ \\
\hline Latvia & $1 / 3 / 2010$ & $22 / 10 / 2010$ & $1 / 5 / 2011$ \\
\hline Lithuania & $11 / 9 / 2003$ & $19 / 5 / 2004$ & $1 / 12 / 2004$ \\
\hline Luxembourg & 13/11/1987 & 25/10/1991 & 1/5/1992 \\
\hline Netherlands & 13/11/1987 & - & - \\
\hline Norway & 13/11/1987 & $3 / 2 / 1988$ & $1 / 5 / 1992$ \\
\hline Portugal & $13 / 11 / 1987$ & $28 / 6 / 1993$ & $1 / 1 / 1994$ \\
\hline Romania & $23 / 6 / 2003$ & $6 / 8 / 2004$ & $1 / 3 / 2005$ \\
\hline Serbia & $2 / 12 / 2010$ & $2 / 12 / 2010$ & $1 / 7 / 2011$ \\
\hline Sweden & 14/3/1989 & $14 / 3 / 1989$ & $1 / 5 / 1992$ \\
\hline Switzerland & $13 / 11 / 1990$ & $3 / 11 / 1993$ & $1 / 6 / 1994$ \\
\hline Turkey & 18/11/1999 & $28 / 11 / 2003$ & $1 / 6 / 2004$ \\
\hline Ukraine & $5 / 7 / 2011$ & - & - \\
\hline
\end{tabular}

Article 10 (Surgical operations) of the Convention states that "Surgical operations for the purpose of modifying the appearance of a pet animal or for other non-curative purposes shall be prohibited, in particular: the docking of tails; the cropping of ears; devocalisation; declawing and defanging. Exceptions to these prohibitions shall be permitted only if a veterinarian considers non-curative procedures necessary either for veterinary medical reasons or for the benefit of any particular animal; to prevent reproduction. Operations in which the animal will or is likely to experience severe pain shall be carried out under 
anaesthesia only by a veterinarian or under his/her supervision. Operations for which no anaesthesia is required may be carried out by a person competent under national legislation". Although it calls for the prohibition of the above-mentioned surgical operations, it specifically acknowledges the right of nations, which otherwise accept the Convention, to reserve their position on the issue.

The Czech Republic as a member state of the Council of Europe signed the European Convention for the Protection of Pet Animals on the $24^{\text {th }}$ of June 1998. The signature was followed by ratification (23 September 1998) and entry into force (24 March 1999). The text of the Convention was implemented in the Czech legislation, namely in Act No. 246/1992 Coll., on the protection of animals against cruelty, as amended (Anon 1992). However, any state may, when signing or depositing its instrument of ratification, acceptance, approval or accession, declare that it will avail itself of the prohibition of the docking of tails. Under this provision of the Convention, the government of the Czech Republic allowed the docking of tails without anaesthesia on piglets, lambs and pups under the age of eight days, provided that the operation is carried out by a competent person within the prescribed time-limit. The age limit for the docking of tails without anaesthesia in piglets was shortened later to 7 days in respect to the legislation of the European Union.

Taking into consideration the aforesaid provisions of the European Convention regarding cosmetic surgery on pets, the Czech Act No. 246/1992 Coll. on the protection of animals against cruelty was amended preventing all cruelty on animals. According to the Czech law, cruelty against an animal can also mean carrying out surgical procedures in order to change the look or other characteristics of an animal, also in cases when the procedures are to be carried out with the use of general or local anaesthesia, pain killers or other methods (with the exception of the cases stated in the law), especially to crop its ears, to damage its vocal cords or control loud vocalisation through other means or for other than health reasons, to extract claws, teeth, poison or scent glands. When the operation is performed by a professionally competent person, anaesthesia is not required in cases of tail docking in piglets of less than 7 days and in lambs and puppies less than eight days old. Not only the aforesaid surgical procedures are prohibited; any exhibition of an animal that has previously undergone such an operation is also forbidden. It is considered as promotion of cruelty on animals. On the other hand, although the docking of tails in puppies is still allowed in the Czech Republic, dogs with natural tails may be equally exhibited and considered to be equal to dogs with docked tails. This policy is in agreement with the Resolution on Surgical Operations in Pet Animals adopted by the Multilateral Consultation of Parties to the European Convention for the Protection of Pet Animals (Council of Europe 1995).

Italy has also signed and recently ratified the Convention (Anon 2010). The Italian government provisionally prohibits the surgical changes to the look of a dog. A legislative measure is the Ordinance on the protection of public safety against dogs' aggressions (Anon 2009). It introduces, though not homogeneously, the prohibition of non-therapeutic surgical procedures or such as done in order to change the look of a dog. The exception is represented, with regard to tail docking, by dogs with tails docked according to their breed standard, until a law on the topic is enacted. The prohibition is based on the premise that such operations cause pain and stress. The use of those procedures is therefore seen as abuse and is punishable by article 544ter of the Act No. 189/2004 on the prevention of animal abuse and the use of the same in illicit fights or unauthorized competitions (Anon 2004).

\section{Position statements}

Considering that tail docking and ear cropping can be painful procedures and are banned in many European countries, they should not be performed for purely cosmetic reasons. Australia, New Zealand and many European countries have banned ear cropping as illegal. 
In Norway, Sweden, Cyprus, Switzerland, Luxembourg, Finland, Germany and parts of Australia tail docking is illegal, as well. In the Czech Republic, tail docking shall not be performed on dogs older than 8 days if there is no medical reason.

In Europe, the Federation of Veterinarians of Europe (FVE, a non-governmental organization, the advisory body within the European Union) is a long-time opponent of tail docking in dogs and speaks out against all surgery on pet animals for non-curative or non-diagnostic purposes, including tail docking, ear cropping, devocalisation and defanging (Federation of Veterinarians of Europe 2001). The Chamber of Veterinary Surgeons of the Czech Republic (KVL ČR 2011) is a member of the Union of European Veterinary Practitioners (UEVP) which is a part of the FVE having a status of an observer. All Czech veterinarians shall follow the Rule of Profession stating that, as there is no medical reason for cropping ears in dogs, veterinary surgeons shall not perform such interventions. In England, where tail-docking has been illegal for a long time, the Royal College of Veterinary Surgeons (RCVS) declared that the docking of tails for other than therapeutic or prophylactic reasons is unethical (Royal College of Veterinary Surgeons 2006). Repeated unethical behaviour may become a subject of disciplinary action. As of 2007, some associations such as the UK Kennel Club have banned the exhibition of dogs with cropped ears or docked tails in dog shows. In Italy, the National Bioethics Committee (Comitato Nazionale per la Bioetica 2006) highlights the fact that, in the name of the bioethical principle banning acts of cruelty, caudectomy and conchectomy, carried out for purely aesthetic reasons, appear ethically non admissible in line with the principle of nonharming, which morally obliges to avoid pain and prevents from harming any living being that can feel pain. Ear cropping and tail docking for merely aesthetic purposes must be considered as harm, since neither a significant benefit (such as the amputation of a leg, therapeutically necessary for survival) nor the observance of a tradition justify them. As for traditional amputations, though somehow consolidated, they follow aesthetic canons that are surely questionable nowadays, non-relevant on the bioethical side and widely opposed by the only professionals who directly take care of animal well-being, i.e. veterinarians.

\section{Discussion}

The issue is largely centered on whether docking and cropping classify as "cruelty". If an activity is believed to be cruel by people, then it is likely to be banned. Similarly, the opinion of people on whether docking and cropping are cruel will shape the way these procedures are dealt with legally. Advocates for docking and cropping compare the procedures to neutering or spaying, and suppose that tail docking and ear cropping are simply practical animal management techniques that should remain available to owners, breeders and veterinarians. "Pro-dockers" argue that docking should be allowed to continue for the following reasons: to prevent injury when hunting dogs work in "close cover" (thick undergrowth), to prevent injury and trouble caused by wagging tails at home, to keep dogs healthy and clean (avoiding faecal contamination around the anus), to make the breed look more ferocious (guard dogs), to prevent abandonment of puppies, if they fail to "look like" the chosen breed, because the breed looks better, more balanced, or "normal" without a tail (Morton 1992). These advocates contend that the tail-docking procedure is either painless or causes so little pain that the puppies' welfare is not compromised. They also contend that, in most cases, the benefits of docking outweigh any brief discomfort. They quote a senior German academic veterinarian who believes that puppies at this age feel little or no pain because their nervous systems have not been fully developed yet. The only published study on tail-docking has shown that puppies shrieked during the procedure. However, vocalisation ceased after an average of 138 seconds. The "shrieking" range was between 8 seconds and 840 seconds (Noonan et al. 1996). 
Most animal welfare groups as well as many veterinary associations have opposed cropping of dog's ears and tail-docking for cosmetic purposes. The Australian Veterinary Association (Department of Agriculture, Fisheries and Forestry 2006) believes that cosmetic tail-docking and ear-cropping of dogs are unnecessary, unjustifiable surgical alterations and are detrimental to the animal's welfare. The World Small Animal Veterinary Association (WSAVA 2001) considers amputation of dogs' tails to be an unnecessary surgical procedure and contrary to the welfare of the dog. The American Veterinary Medical Association (AVMA 2005) has been encouraging veterinarians to make dog owners aware of the risks and lack of medical benefits in this regard. Canadian Veterinary Medical Association (CVMA 2005) opposes surgical alteration of any animal for purely cosmetic purposes and recommends that breed associations change their breed standards so that cosmetic procedures are not required. Similarly, the Association of Veterinarians for Animal Rights (AVAR 2010) opposes surgery of various kinds performed to meet "breed standards" or to correct so-called vices. Procedures such as ear cropping, tail docking, or debarking in dogs, or declawing in cats are unacceptable because the suffering and disfigurement they cause to an animal are not compensated by any benefits to the animal. If any such procedure can be shown to be necessary for medical or humane reasons, then it can be allowed. Dogs' "breed standards" must be altered to allow the animals to be exhibited without being surgically mutilated.

In conclusion, veterinarians should counsel and educate dog owners not to have these procedures performed unless medically necessary. Therefore, veterinarians who wish to be seen as caring professionals and guardians of animal welfare must stop cosmetic tail docking and actively oppose anyone continuing this painful practice. In light of the previous considerations, Italian anti-cruelty laws must be changed to specifically include cosmetic ear cropping and tail docking as was done in the Czech Republic. These laws cannot simply forbid these procedures, considering these as ill-treatments, but they must sanction all misuses. In contrast to the Czech Republic, legislation in Italy designed to promote animal welfare does not specifically address this issue and ear cropping and tail docking are currently culturally acceptable, therefore, it is difficult to prosecute dog owners for subjecting their animals to these procedures.

\section{References}

American Veterinary Medical Association (AVMA) 2005: Ear cropping and tail docking. Available at: www. avma.org/issues/policy/animal_welfare/tail_docking.asp. Last modified November 2008. Accessed December 19,2011

Anon 1992: Act No. 246/1992 Coll., on the protection of animals against cruelty. Sbírka zákonů (Collection of Laws) 50: 1284-1290

Anon 2004: Law No. 189/2004, on the prevention of animal abuse and the use of the same in illicit fights or unauthorized competitions. Official Journal 178: 4-8

Anon 2009: Ordinance on the protection of public safety against dogs' aggressions. Official Journal (General Series) 68: 49-50

Anon 2010: Law No. 201/2010 on ratification and implementation of the European Convention for the protection of pets. Official Journal 283: 1-27

Association of Veterinarians for Animal Rights (AVAR) 2010: Position Statement: Cosmetic Surgery or Surgery to Correct 'Vices'. Available at: www.cdb.org/vets/vets_ar.htm. Accessed December 19, 2011

Canadian Veterinary Medical Association (CVMA) 2005: Cosmetic surgery. Available at: www. canadianveterinarians.net/ShowText.aspx?ResourceID=46. Last modified July, 2007. Accessed December 19, 2011

Chamber of Veterinary Surgeons of the Czech Republic (KVL ČR) 2011: Rule of profession. Available at: www. vetkom.cz/content/showPage/profesni-rad-88. Accessed December 19, 2011

Comitato Nazionale per la Bioetica 2006: Caudotomia e conchectomia. Available at: www.governo.it/bioetica/ testi/caudotomia conchectomia.pdf. Accessed December 19, 2011

Council of Europe 1987: The European convention for the protection of pet animals. European Treaty Series No. 125

Council of Europe 1995: Resolution on surgical operations on pet animals adopted by the Multilateral Consultation of Parties to the European convention for the protection of pet animals (ETS 125) on 10 March 1995 
Council of Europe 2011: European convention for the protection of pet animals - chart of signatures and ratifications (Status as of 20/12/2011). Available at: conventions.coe.int/Treaty/Commun/ChercheSig. asp?NT=125\&CM=1\&DF=20/12/2011\&CL=ENG. Accessed December 20, 2011

Department of Agriculture, Fisheries and Forestry 2006: Australian Animal Welfare Strategy. Review of existing animal welfare arrangements for the companion animals working Group. Available at: www.daff.gov.au/ data/assets/pdf_file/0018/152109/aaws_stocktake_companion.pdf. Accessed December 20, 2011

Federation of Veterinarians of Europe (FVE) 2001: Surgery for cosmetic and other non-curative purposes. Available at: www.fve.org/news/position_papers/animal_welfare/fve_00_066_cosmetic_surgery.pdf. Accessed December 19, 2011

Hancock WB 1968: Ear-cropping technic. Vet Med Small Anim Clin 63: 860-865

Jensen HE 1950: Ear trimming. J Am Vet Med Assoc 116: 428-431

Leonard HC 1958: Ear cropping by triangulation. J Am Vet Med Assoc 133: 108-110

Morton D 1992: Docking of dogs: Practical and Ethical Aspects. Vet Rec 131: 301-306

Noonan GJ, Rand JS, Blackshaw JK, Priest J 1996: Behavioural observations of puppies undergoing tail docking. Appl Anim Behav Sci 49: 335-342

Royal College of Veterinary Surgeons (RCVS) 2006: RCVS welcomes ban on cosmetic tail-docking of dogs. Available at: www.rcvs.org.uk/news-and-events/news/rcvs-welcomes-ban-on-cosmetic-tail-docking-of-dogs/. Accessed December 19, 2011

World Small Animal Veterinary Association (WSAVA) 2001: WSAVA tail docking position statement. Available at: www.wsava.org/taildock.htm. Accessed December 19, 2011 